\title{
Do Psychological Factors Predict Poor Outcome in Patients Undergoing TKA? A Systematic Review
}

\author{
Yasser Khatib MBBS, MSports Med, FRACS(Orth), \\ Aman Madan BSc(Med), MBBS, Justine M. Naylor PhD, BAppSc(Phty), \\ Ian A. Harris MBBS, MMed(Clin Epi), PhD, FRACS(Orth)
}

Received: 21 October 2014/Accepted: 25 February 2015/Published online: 20 March 2015

(C) The Association of Bone and Joint Surgeons \& 2015

\begin{abstract}
Background A subgroup of patients undergoing TKA is unhappy with the outcome of surgery and preoperative psychological factors may play a role in their dissatisfaction. Questions/purposes We asked whether (1) psychological factors, as measured by preoperative self-reported questionnaires, predicted poor outcome after TKA, and (2) whether certain psychological factors examined predicted poor outcome better than others.

Methods We performed a systematic review and metaanalysis of prospective observational studies published in

Each author certifies that he or she has no commercial associations (eg, consultancies, stock ownership, equity interest, patent/licensing arrangements, etc) that might pose a conflict of interest in connection with the submitted article.

All ICMJE Conflict of Interest Forms for authors and Clinical Orthopaedics and Related Research ${ }^{\circledR}$ editors and board members are on file with the publication and can be viewed on request. Each author certifies that his or her institution has approved the human protocol for this investigation and that all investigations were conducted in conformity with ethical principles of research, and that informed consent was obtained.

This research was conducted at the Whitlam Orthopaedic Research Centre, Ingham Institute for Applied Medical Research, Liverpool Hospital, Sydney, Australia.
\end{abstract}

Electronic supplementary material The online version of this article (doi:10.1007/s11999-015-4234-9) contains supplementary material, which is available to authorized users.

\section{Y. Khatib ( $($ )}

Whitlam Orthopaedic Research Centre, Ingham Institute for Applied Medical Research, UNSW, 1 Campbell Street,

Liverpool, NSW 2170, Australia

e-mail: yasser@carefirstortho.com.au

Y. Khatib

PO Box 949, Penrith, NSW 2750, Australia
MEDLINE, CINAHL ${ }^{\circledR}$, EMBASE ${ }^{\mathrm{TM}}$, and PsycINFO ${ }^{\circledR}$ databases from their date of inception to October 2013, augmented with a manual search of bibliographies. Study eligibility was performed according to an a priori protocol. Included studies were assessed for quality according to the Newcastle-Ottawa scale. Two reviewers independently performed the search, identified eligible studies, assessed their methodologic quality, and extracted data. Outcomes of interest included postoperative dissatisfaction, pain, or limited function of the patients.

Results A total of 19 studies (17 cohort studies and two cross-sectional surveys) containing data on 9046 TKAs performed in 8704 adult patients were included in the review. Mean patient age was 68 years and followup ranged from 6 to 60 months (mean study followup, 14 months). Clinical and methodologic heterogeneity in study design prevented the statistical pooling of data and subsequent meta-analysis. Dissatisfaction rates with TKA ranged from $7.5 \%$ to $28.3 \%$. Psychological health was deemed a significant predictor of satisfaction, pain, or function at a minimum of 6 months after TKA in 16 studies. The remaining three studies did not find this relationship. Baseline mental health factors may affect patient satisfaction, their long-term perception of pain, and their motivation to return to the desired level of function. We were unable to determine the most relevant psychological

\section{A. Madan, J. M. Naylor, I. A. Harris}

Whitlam Orthopaedic Research Centre, Ingham Institute for Applied Medical Research, Liverpool Hospital, Sydney, NSW, Australia 
states or the most appropriate way to assess them with our systematic review.

Conclusions The preoperative psychological state of a patient may affect the outcome after a TKA. A comprehensive psychological assessment of patients is required to examine the long-term effect of such psychological factors on the eventual outcomes of TKA once the recovery phase is complete and to assess the effect that treatment for these psychological conditions may have on decreasing the dissatisfaction rate with TKA in this population.

\section{Introduction}

A TKA is a common procedure for treatment of symptoms of advanced knee osteoarthritis and its incidence is steadily increasing. The Australian Orthopaedic Association National Joint Replacement Registry reported 42,202 TKAs in 2012, an increase of $4.1 \%$ compared with 2011, and a 92.4\% increase since 2003 [2]. The Canadian Joint Replacement Registry noted an increase of $15 \%$ in TKAs performed from 2006 to 2010 and 2011 [12]. In the United States, more than 500,000 TKAs are performed annually and the number is expected to exceed 3.5 million annually by 2030 [30]. Leskinen et al. reported a 130-fold increase in the incidence of TKAs in Finland during a 26-year period with 65 TKAs performed per 100,000 inhabitants between 30 and 59 years old [31].

Despite increasing demand for TKAs and cost-effectiveness of the procedure $[11,16,17]$, a substantial number of patients who undergo a TKA are dissatisfied with the outcomes, with reported satisfaction rates varying between $75 \%$ and $89 \%[1,6,7,23,24,36,41,51]$, regardless of patient demographics or severity of disease.

Psychological factors have been shown to influence recovery in many surgical fields including orthopaedic, abdominal, breast, and oncologic surgery [21, 35, 45]. Preoperative psychological factors of patients such as anxiety, depression, catastrophizing state, poor self-efficacy, and poor coping skills may be preoperative predictors of unsatisfactory patient outcomes after joint replacement surgery [3, 15, 19, 20, 33, 42]. The duration and magnitude of the effect these factors have on postoperative outcomes remains unclear.

The aim of our study was to perform a systematic review of prospective observational studies to examine (1) whether psychological factors, as measured by preoperative selfreported questionnaires, predicted poor outcome (measured by patient satisfaction, pain, and function) after TKA, and (2) whether some psychological factors predicted poor outcome better than others.

\section{Patients and Methods}

An a priori protocol for identifying relevant literature was followed. Two investigators (YK, AM) independently and systematically conducted an electronic search of MEDLINE, CINAHL ${ }^{\circledR}$, PsycINFO ${ }^{\circledR}$, and EMBASE $^{\mathrm{TM}}$, to identify studies examining the effect of mental health, catastrophizing, anxiety, depression, and self-efficacy on outcomes of TKA. Database searches were conducted from the date of inception of the database to October 2013. The search was augmented with a manual search through bibliographies of retrieved papers. Search strategies incorporated relevant keywords and subject headings (Appendix 1 . Supplemental materials are available with the online version of $\mathrm{CORR}^{\circledR}$ ).

All titles from the search were exported into a citation management program (EndNote ${ }^{\circledR}$ X6.01; Thomson Reuters, Philadelphia, PA, USA). Duplicates were removed and abstracts retrieved. All titles were screened for inclusion and irrelevant titles removed. If relevant, article abstracts were read to ascertain their eligibility for inclusion.

To be included, articles had to be prospective studies in adults undergoing joint replacement surgery. Retrospective studies were excluded owing to the risk of recall bias in determining psychological status. Eligible studies had to have a measurement of a preoperative psychological factor included, such as anxiety or depression, and evaluated with at least one reliable and validated self-reporting instrument. The studies also had to include at least one reliable and valid clinical measurement tool assessing patient-reported or objectively measured knee function before and after TKA.

Studies also were required to provide a comparison of the clinical outcomes, specifically, patient satisfaction, pain, and/or function after TKA, based on preoperatively measured psychological factors. A minimum followup of 6 months was required. The minimum time was chosen owing to evidence indicating that improvement at 6 months has been shown to be an approximation for improvement at 12 months [22, 29, 43] and 24 months [40]. Studies that reported results of TKA together with other types of replacement surgery, including THA or unicompartmental knee arthroplasty, were included if the data for TKA outcomes could be isolated.

No restriction was placed on language or publication date and a translation service was used for studies published in languages other than English if required. In the case of duplicate publications or publications that used the same set of patient data, only the most complete paper was included, or the first publication if patient numbers were identical. 


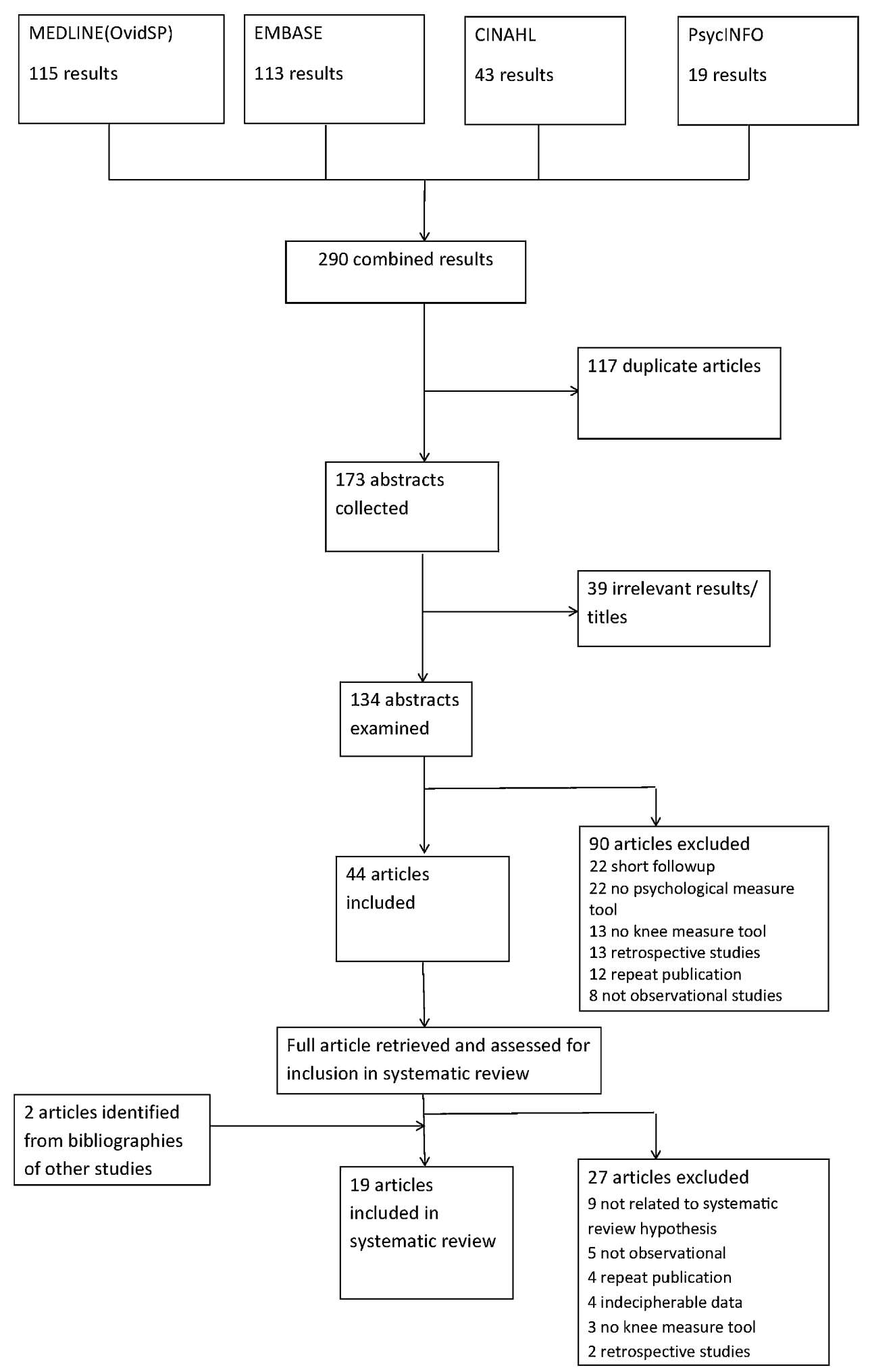

Fig. 1 A flow diagram of the study inclusion criteria is shown.

Each author independently and systematically screened each reference for potential inclusion and compiled a list of included and excluded articles. Disagreement regarding inclusion was resolved by discussion to achieve consensus. In total, 19 articles met the inclusion criteria for our review (Fig. 1). 
Table 1. Summary of characteristics of the studies included in this review

\begin{tabular}{|c|c|c|c|c|c|c|c|c|c|c|}
\hline Study & $\begin{array}{l}\text { Level of } \\
\text { evidence }\end{array}$ & $\begin{array}{l}\text { Study } \\
\text { design }\end{array}$ & $\begin{array}{l}\text { Study } \\
\text { size }\end{array}$ & $\begin{array}{l}\text { Number } \\
\text { of TKR }\end{array}$ & $\begin{array}{l}\text { Females } \\
(\%)\end{array}$ & $\begin{array}{l}\text { Mean } \\
\text { age } \\
\text { (years) }\end{array}$ & $\begin{array}{l}\text { Followup } \\
\text { period } \\
\text { (months) }\end{array}$ & $\begin{array}{l}\text { Followup } \\
\text { rate }(\%)\end{array}$ & $\begin{array}{l}\text { Power } \\
\text { analysis }\end{array}$ & $\begin{array}{l}\text { Mean } \\
\text { NOS }\end{array}$ \\
\hline Ayers et al. [3] & $\begin{array}{l}\text { Prognostic } \\
\text { level } 1\end{array}$ & Cohort study & 165 & 165 & $103(62)$ & 68 & 12 & 100 & $\mathrm{~N}$ & 5 \\
\hline Blackburn et al. [5] & NS & Cohort study & 40 & 40 & $24(60)$ & 72 & 6 & 100 & $\mathrm{~N}$ & 5 \\
\hline Brander et al. [9] & NS & Cohort study & 116 & 149 & $64(55)$ & 66 & 12 & NS & $\mathrm{N}$ & 6 \\
\hline Brander et al. [8] & $\begin{array}{l}\text { Prognostic } \\
\text { level } 1\end{array}$ & Cohort study & 83 & 109 & $46(55)$ & 66 & 60 & 71.6 & $\mathrm{~N}$ & 6.5 \\
\hline Ellis et al. [13] & $\begin{array}{l}\text { Prognostic } \\
\text { level } 1\end{array}$ & Cohort study & 154 & 154 & $110(71)$ & 62 & 12 & 82 & $\mathrm{~N}$ & 6 \\
\hline Engel et al. [14] & NS & Cohort study & 117 & 117 & $60(51)$ & 67 & 6 & NS & $\mathrm{N}$ & 4 \\
\hline Escobar et al. [15] & NS & $\begin{array}{l}\text { Cross-sectional } \\
\text { survey }\end{array}$ & 640 & 640 & $471(74)$ & 72 & 6 & 74.9 & $\mathrm{~N}$ & 7 \\
\hline Gandhi et al. [18] & NS & $\begin{array}{l}\text { Cross-sectional } \\
\text { survey }\end{array}$ & 1720 & 1720 & $1005(58)$ & 70 & 12 & 74.8 & $\mathrm{~N}$ & 6 \\
\hline Heck et al. [24] & NS & Cohort study & 291 & 330 & $182(63)$ & 70 & 24 & 92 & $\mathrm{~N}$ & 7 \\
\hline Jones et al. [26] & NS & Cohort study & 276 & 276 & $162(59)$ & 69 & 6 & 79.5 & $\mathrm{~N}$ & 7 \\
\hline Judge et al. [27] & NS & Cohort study & 1991 & 1991 & $1214(61)$ & 71 & 6 & 55.2 & $\mathrm{~N}$ & 7 \\
\hline Kim et al. [28] & NS & Cohort study & 270 & 438 & $261(97)$ & 68 & 12 & 69.7 & $\mathrm{~N}$ & 7 \\
\hline Lingard \& Riddle [34] & $\begin{array}{l}\text { Prognostic } \\
\text { level } 1\end{array}$ & Cohort study & 952 & 952 & $574(60)$ & 71 & 24 & 69.2 & $\mathrm{~N}$ & 6 \\
\hline Papakostidou et al. [37] & NS & Cohort study & 204 & 204 & $162(79)$ & 69 & 12 & 90 & $\mathrm{~N}$ & 7 \\
\hline Riddle et al. [39] & $\begin{array}{l}\text { Prognostic } \\
\text { level } 1\end{array}$ & Cohort study & 140 & 140 & $111(79)$ & 64 & 6 & 89.2 & $\mathrm{Y}$ & 7.5 \\
\hline Scott et al. [44] & NS & Cohort study & 1141 & 1217 & $698(61)$ & 70 & 12 & 94 & $\mathrm{Y}$ & 7 \\
\hline Smith \& Zautra [46] & NS & Cohort study & 64 & 64 & $37(58)$ & 67 & 6 & 88.9 & $\mathrm{~N}$ & 7 \\
\hline Sullivan et al. [47] & NS & Cohort study & 120 & 120 & $73(61)$ & 67 & 12 & NS & $\mathrm{N}$ & 7 \\
\hline Wylde et al. [50] & NS & Cohort study & 220 & 220 & $137(62)$ & 70 & 12 & 88 & $\mathrm{~N}$ & 6 \\
\hline
\end{tabular}

$\mathrm{TKR}=$ total knee replacements; $\mathrm{N}=$ no; $\mathrm{Y}=$ yes; NS = not specified; Mean NOS = mean Newcastle Ottawa Score of the two investigators who assessed quality of research in the included studies.

Included studies were assessed independently by two reviewers (YK, AM) for quality, with reference to the Cochrane Reviewers' Handbook [25]. Risk of bias was assessed using the Newcastle-Ottawa Quality Assessment Scale [48], a tool used to assess the quality of cohort and case-controlled studies included in systematic reviews. Each study was assessed on eight items in three domains: group selection, comparability, and ascertainment of exposure/ outcome. A star system was used, with a star awarded to high-quality items and a maximum possible score of nine stars. There was $89 \%$ agreement in the quality rating between the two investigators. Only two studies justified their sample size and provided a power analysis $[39,44]$. All studies had a minimum 6-month followup period. The length of followup ranged from 6 to 60 months, with most (16 studies) between 6 and 12 months (mean study followup, 14 months; median, 12 months). The followup rate was at least $80 \%$ in 10 studies and $70 \%$ to $80 \%$ in another four (mean followup rate, $82 \%$ ) (Table 1).
Of the 19 studies, there were 17 cohort studies $[3,5,8$, $9,13,14,24,26-28,34,37,39,44,46,47,50]$ and two cross-sectional surveys $[15,18]$, including five level 1 prognostic studies $[3,8,13,34,39]$. The studies were conducted in seven countries: 10 in the USA $[3,5,8,9,13$, $14,24,34,39,46]$; four in the UK [27, 34, 44, 50]; four in Canada; [18, 26, 34, 47]; and one each in Australia [34], Spain [15], Greece [37], and Korea [28]. Most studies (17) were conducted in metropolitan populations; one study was a multinational cohort study conducted in 13 centers in four countries (UK, USA, Australia, and Canada) [34]. One study included a rural and metropolitan population [37] and one included only patients from indigent backgrounds [13]. In total, our review reports on studies including 9046 TKAs performed in 8704 patients, of which 5494 (63\%) were women. The mean age of patients from all included studies was 68 years (range, 64-72 years).

There was considerable heterogeneity in the self-reported psychological questionnaires used to measure 
baseline mental health of the patients. Nine studies relied on the Mental Component Subscale score of SF-36 or SF-12 [3, 14, 15, 18, 24, 26, 28, 34, 44]. Two other studies $[8,9]$ used the State Trait Anxiety Index and the Beck Depression Index. Two studies used the Pain Catastrophizing Scale [39, 47]. Other psychological assessment tools included the Self-Efficacy Scale [50], Purpose In Life [46], Patient Health Questionnaire [13], Hospital Anxiety and Depression scale [5], and the Centre for Epidemiological Studies Depression scale [37]. The heterogeneity in the use of psychological tools and outcomes precluded data pooling for the purposes of performing a meta-analysis.

Fifteen studies used the WOMAC to measure patientreported pain and function outcomes after surgery [3, 9, 13-15, 18, 24, 26, 28, 34, 37, 39, 46, 47, 50]. The Oxford Knee Score was used in three other studies [5, 27, 44] and the Knee Society Score was used in two studies [8, 9]. Patient satisfaction was assessed directly in only five studies [18, 24, 27, 28, 44], measured using a four-point Likert scale in three $[18,28,44]$ and a three-point scale in another study [24]. One study used a 100-mm VAS and asked the patients to mark how satisfied they were with the procedure [27]. A value greater than $50 \mathrm{~mm}$ was considered satisfactory in terms of patient assessment.

Two authors (YK, AM) independently extracted data from the included articles, such as the country or countries where the study was done, name of the lead author, year of publication, level of evidence (if specified), study design, cohort size, proportion of women patients in the study population, length of followup, and followup rate. Instruments used to assess psychological status and knee function also were recorded.

The primary outcome of interest was the relation of baseline mental health factors with postoperative patient dissatisfaction after TKA. The dissatisfaction rate was recorded or calculated from the study where possible. Dissatisfaction was defined as any patient who reported being unhappy or unsure about the benefit from the TKA at least 6 months after surgery.

Secondary outcomes were the relationships of baseline mental health factors with postoperative patient pain and function levels as reported on knee-scoring tools. The magnitude of effect of baseline mental health on postoperative pain and function was recorded. All data were tabulated and compared between the two authors (YK, AM) and discrepancies were resolved by discussion and a review of results from the original article.

\section{Results}

Fifteen studies in our review showed that baseline psychological factors contributed to postoperative outcomes defined as patient satisfaction with the results of TKA, persistent pain, or poor function. Four studies (867 patients with mean age of 68 years, including 645 [74\%] female patients) showed no association between psychological factors and postoperative outcomes of patient satisfaction, persistent pain, and poor function. We sought to compare the two groups of studies for other confounders in patients, such as BMI, disease severity, number of comorbidities, welfare standing, and socioeconomic status. We were able to assess the two groups for only mean age and percentage of female patients (Table 1). Other factors were inconsistently reported and insufficient information was available for comparison, thus a meaningful analysis of pooled data could not be performed to show the effect of these potential confounders on overall satisfaction rates.

Patient dissatisfaction rate with TKA outcome was stated or could be calculated in only five studies (Table 2). Dissatisfaction ranged from $7.5 \%$ to $28.3 \%$ (median, $18.6 \%$ ). Psychological health was deemed a significant predictor in satisfaction at a minimum followup of 6 months after TKA in four studies [18, 24, 27, 44]; another study attributed patient dissatisfaction to postoperative stiffness, but did not comment on the effect of mental health state of patients [28].

The relationship between patient baseline mental health factors and persistent postoperative pain was reported in 13 studies (Table 2) for a total of 6095 patients. Twelve articles showed a statistically significant relationship with higher rates of persistent pain in the group of patients with mental health factors. In the remaining article, Escobar et al. [15] reported a similar trend, but the trend did not reach statistical significance $(\mathrm{p}=0.09)$. Although pooling the results for meta-analysis was not possible, conclusions from the studies regarding the effect of mental health factors on pain after undergoing TKA were similar. Preoperative anxiety or depression was deemed a significant predictor of postoperative pain in seven of 13 studies reporting the association. The remaining six studies did not examine these states specifically but showed that lower preoperative mental health scores had similar postoperative associations [8, 9, $13,27,46,47,50]$. Pain scores in the patient population with anxiety, depression, or lower mental health scores were elevated at baseline and at all assessment points [13, $27,28,34,37,47,50$ ] for up to 2 years in one study [34 ]. Lingard and Riddle [34] estimated the effect to be 3 to 5 points lower on the 20-point pain component of the WOMAC, indicating worse pain in the group of patients with lower mental health scores. Two studies $[39,47]$ that examined the correlation between patient pain after TKA and the Pain Catastrophizing Scale found a statistically significant relationship. Riddle et al. [39] found that a Pain Catastrophizing Scale score of 16 or greater predicted less than $50 \%$ improvement in WOMAC pain score 
Table 2. Summary of results from studies included in this review

\begin{tabular}{|c|c|c|c|c|c|c|}
\hline Study & Knee tool & Psychological tool & $\begin{array}{l}\text { Did psychological } \\
\text { factors predict outcome }\end{array}$ & $\begin{array}{l}\text { Dissatisfaction } \\
\text { rate }(\%)\end{array}$ & Pain & Function \\
\hline Ayers et al. [3] & WOMAC & SF-36 MCS & $\mathrm{Y}$ & NS & NS & $\mathrm{Y}$ \\
\hline Blackburn et al. [5] & $\mathrm{OKS}$ & HAD & $\mathrm{Y}$ & NS & NS & $\mathrm{Y}$ \\
\hline Brander et al. [9] & KSS, WOMAC & BDI, STAI & $\mathrm{Y}$ & NS & $\mathrm{Y}$ & $\mathrm{Y}$ \\
\hline Brander et al. [8] & KSS & BDI, STAI & Y & NS & $\mathrm{Y}$ & $\mathrm{Y}$ \\
\hline Ellis et al. [13] & WOMAC & PHQ & $\mathrm{Y}$ & NS & $\mathrm{Y}$ & $\mathrm{Y}$ \\
\hline Engel et al. [14] & WOMAC & SF-36 MCS & $\mathrm{N}$ & NS & NS & $\mathrm{Y}$ \\
\hline Escobar et al. [15] & WOMAC & SF-36 MCS & $\mathrm{Y}$ & NS & $\mathrm{N}$ & $\mathrm{Y}$ \\
\hline Gandhi et al. [18] & WOMAC & SF-36 MCS & $\mathrm{Y}$ & 25 & NS & NS \\
\hline Heck et al. [24] & WOMAC & SF-36 MCS & $\mathrm{Y}$ & 12 & NS & $\mathrm{Y}$ \\
\hline Jones et al. [26] & WOMAC & SF-36 MCS & $\mathrm{N}$ & NS & NS & $\mathrm{N}$ \\
\hline Judge et al. [27] & OKS & EQ5D & $\mathrm{Y}$ & 28.3 & $\mathrm{Y}$ & $\mathrm{Y}$ \\
\hline Kim et al. [28] & WOMAC & SF-36 MCS & $\mathrm{N}$ & 7.5 & $\mathrm{Y}$ & $\mathrm{Y}$ \\
\hline Lingard \& Riddle [34] & WOMAC & SF-36 MCS & $\mathrm{Y}$ & NS & $\mathrm{Y}$ & $\mathrm{N}$ \\
\hline Papakostidou et al. [37] & WOMAC & CESD & $\mathrm{N}$ & NS & $\mathrm{Y}$ & NS \\
\hline Riddle et al. [39] & WOMAC & PCS & Y & NS & $\mathrm{Y}$ & $\mathrm{N}$ \\
\hline Scott et al. [44] & OKS & SF-12 & $\mathrm{Y}$ & 18.6 & $\mathrm{Y}$ & $\mathrm{N}$ \\
\hline Smith \& Zautra [46] & WOMAC & PIL & Y & NS & $\mathrm{Y}$ & $\mathrm{Y}$ \\
\hline Sullivan et al. [47] & WOMAC & PCS & Y & NS & $\mathrm{Y}$ & $\mathrm{N}$ \\
\hline Wylde et al. [50] & WOMAC & SES, HAD & $\mathrm{Y}$ & NS & $\mathrm{Y}$ & NS \\
\hline
\end{tabular}

MCS = Mental Component Score; NS = not specified; OKS = Oxford Knee Score; HAD = Hospital Anxiety and Depression Scale; Y = yes, the authors in each study examined the effect of baseline psychological factors and found that they did have an effect on postoperative outcomes related to pain and function scores; $\mathrm{N}=$ no, the authors in each study examined the effect of baseline psychological factors and found that they did not have an effect on postoperative outcomes related to pain and function scores; KSS $=$ The Knee Society Scoring System ${ }^{\odot}$; BDI $=$ Beck Depression Index; STAI = State-Trait Anxiety Index; PHQ = Patient Health Questionnaire; EQ5D = European Quality of Life-5 Dimensions; CESD = Centre for Epidemiological Studies Depression Scale; PCS = Pain Catastrophizing Scale; PIL = Purpose in Life; SES = Self-efficacy Scale.

(odds ratio $[\mathrm{OR}], 2.67 ; 95 \% \mathrm{CI}, 1.2-6.1$; $\mathrm{p}=0.02$ ). In sensitivity analysis, a Pain Catastrophizing Scale score of 16 or greater predicted poor outcome as defined by a minimal clinically important improvement in the WOMAC score of four points or less (OR, 6.04; 95\% CI, 1.75 - 20.81; $\mathrm{p}=0.005)$.

The effect of baseline mental health on postoperative function was assessed in 16 studies [3, 5, 8, 9, 13-15, 24, 26-28, 34, 39, 44, 46, 47]. Eleven articles [3, 5, 8, 9, 13$15,24,27,28,46]$ showed a statistically significant relationship between baseline mental health factors and various aspects of functional recovery after TKA.

Patients with anxiety or depression improved their overall knee scores but their scores in function did not improve as much as those of patients who did not have anxiety and depression [5, 8, 9]. After adjustment for comorbidities, emotional health, anxiety, and depression were predictors of improvement in physical function [3]. Preoperative depression influenced knee function scores at 5 years, contributing to an approximately $10 \%$ difference compared with scores of patients without depression ( $\mathrm{p}=0.01$ ) [5, 8, 13-15, 27, 28, 46]. Smith and Zautra [46] also showed that patients with lower baseline mental health scores had less improvement in functional scores postoperatively; however, they found no association between baseline mental health and postoperative stiffness. Heck et al. [24] found an improvement in the level of patient function measured by the SF-36 Physical Component Score in patients with better baseline mental health (defined by the SF-36 Mental Component Score).

The remaining five studies explored the relationship between preoperative patient mental health status and postoperative physical function without establishing a significant correlation [26, 34, 39, 44, 46]. Lingard and Riddle [34] showed that in distressed patients with low SF36 Mental Component Scores, the only significant difference in WOMAC function was at baseline, with no significant difference at 12 and 24 months after surgery.

While most studies measured the general mental health status using self-reported questionnaires, some assessed particular states such as anxiety, depression, and pain catastrophizing. Brander et al. [8, 9] examined the effects of depression and anxiety on pain and function in a cohort of patients during a 5-year period after TKA and found that preoperative midrange anxiety scores were a strong predictor of pain 1 year after TKA but did not remain a predictor of pain at 5 years, whereas preoperative 
depression was associated with long-term pain only at 5 years. Other studies did not compare different psychological states and did not comment on the individual contribution of each state to the overall effect on outcomes after TKA, thus we could not deduce whether certain psychological factors predicted poor outcome more than others.

\section{Discussion}

A TKA is a successful procedure for relief of symptoms of advanced arthritis and is associated with improvements in knee-related outcome measures. However, overall analysis of group-based results masks the presence of a proportion of patients who are dissatisfied after surgery. In our review, we found that this dissatisfaction rate ranged from $7.5 \%$ to 28.3\%. The dissatisfaction was evident in many kneespecific patient-rated outcome scores and may be more evident in scoring systems that rely on subjective patientbased ratings rather than physician-based rating measures that rely on objective measurements, such as ROM and radiographic alignment. Surgeon rating and patient rating of success after surgery differ and may not correlate [10]. The divergence becomes more pronounced in patients who are dissatisfied with the outcome of their procedure [32]. Our systematic review showed that preoperative psychological factors influence patients' postsurgical outcomes, including persistent pain, reduced level of function, and overall satisfaction with the procedure.

Our study has numerous limitations. Most of the articles included in our review achieved acceptable quality assessments; however, they were observational studies with inherent weaknesses and limitations. The heterogeneity in data also precluded pooling for meta-analysis. Our study would have been more informative if a summary effect estimate could have been reported. Although we limited the followup period to more than 6 months to minimize the dissatisfaction that may occur owing to acute pain and discomfort after surgery, we recognize that improvement from TKA may extend well beyond this period [38, 43, 49]. The inclusion of studies which examine the outcomes of TKA after a period of 6 months may bias the results of TKA and exaggerate the effect that baseline psychological factors could have on pain, function, and satisfaction which are known to continue to improve and do not plateau until at least 2 years after surgery. Furthermore, none of the studies included in this review made a formal clinical assessment of patient mental health; rather all data regarding psychological health factors were derived from patient self-report questionnaires. This might exaggerate the influence these reported factors have on the outcomes of TKA. Finally, there may be potential bias in the lack of clarity in studies reporting on possible confounders previously implicated in patient dissatisfaction after TKAs, such as female sex, younger age, and higher BMI. Numerous studies failed to report these factors despite reportedly collecting the data. Consequently, meaningful analysis could not be performed to show the effect of these factors independently of patient psychological status. However, we did take steps to limit bias, including conducting the study according to an a priori protocol with detailed inclusion criteria for article selection and data abstraction, performing key steps in duplicate, not limiting the publication date or language, excluding retrospective articles, and using an experienced librarian to formulate our search strategy.

Baker et al. [4] reported that persistent postoperative pain and poor function were significant predictors of postoperative patient dissatisfaction. In addition to direct measurement of satisfaction, we also examined the effect of baseline mental health factors on postoperative pain and function. Anxiety, depression, and pain catastrophizing are some of the important factors that influence postoperative outcomes. However, there was a lack of clarity in identifying which of these factors or states have the greatest influence on postoperative outcomes. This was largely attributable to the variability in measurement instruments used in the studies to assess these factors.

Aspects of patient psychology before undergoing TKA are likely to play an important role in postoperative recovery and the patient's perception of the success of surgery. While self-reported questionnaires offer a glimpse of psychological health, they offer only a cursory assessment of the nature and severity of these states. Research should be conducted to determine if patients who show psychological risk factors for poor outcome (either on relevant questionnaires or during actual psychological evaluation), have better outcomes with psychological intervention or treatment before undergoing TKA.

Our second aim was to compare the effect of particular psychological states such as depression, anxiety, or pain catastrophizing on the eventual outcomes of TKA. We were unable to do this as most studies examined only one aspect with self-reporting questionnaire(s) and a comprehensive evaluation of individual psychological factors was not performed. To address this goal of comparing states and identifying the psychological issues of primary importance, prospective research would need to be conducted which provides a relatively comprehensive evaluation of each psychological factor and assesses its relative contribution to eventual outcomes measured at least 2 years after recovery from surgery.

A patient dissatisfaction rate of up to $28 \%$ after TKA is high and must be addressed. Preexisting psychological factors may be treatable, thus possibly altering patient outcome after surgery. A form of preoperative psychological assessment may 
be beneficial in understanding patients' expectations and influence patient selection, education, and the timing of surgery. Future research should focus on identifying the main mental health states or psychological factors that influence postsurgical outcomes and ways to measure the prevalence and severity of such states in patients considered suitable candidates for TKA.

\section{References}

1. Anderson JG, Wixson RL, Tsai D, Stulberg SD, Chang RW. Functional outcome and patient satisfaction in total knee patients over the age of 75. J Arthroplasty. 1996;11:831-840.

2. Australian Orthopaedic Association. Hip and Knee Arthroplasty. Annual report 2013. Available at: https://aoanjrr.dmac.adelaide. edu.au/documents/10180/127202/Annual\%20Report\%202013? version $=1.2 \& \mathrm{t}=1385685288617$. Accessed February 16, 2014.

3. Ayers DC, Franklin PD, Ploutz-Snyder R, Boisvert CB. Total knee replacement outcome and coexisting physical and emotional illness. Clin Orthop Relat Res. 2005;440:157-161.

4. Baker PN, van der Meulen JH, Lewsey J, Gregg PJ; National Joint Registry for England and Wales. The role of pain and function in determining patient satisfaction after total knee replacement: data from the National Joint Registry for England and Wales. J Bone Joint Surg Br. 2007;89:893-900.

5. Blackburn J, Qureshi A, Amirfeyz R, Bannister G. Does preoperative anxiety and depression predict satisfaction after total knee replacement? Knee. 2012;19:522-524.

6. Bonnin M, Laurent JR, Parratte S, Zadegan F, Badet R, Bissery A. Can patients really do sport after TKA? Knee Surg Sports Traumatol Arthrosc. 2010;18:853-862.

7. Bourne RB, Chesworth BM, Davis AM, Mahomed NN, Charron KD. Patient satisfaction after total knee arthroplasty: who is satisfied and who is not? Clin Orthop Relat Res. 2010;468:57-63.

8. Brander V, Gondek S, Martin E, Stulberg SD. Pain and depression influence outcome 5 years after knee replacement surgery. Clin Orthop Relat Res. 2007;464:21-26.

9. Brander VA, Stulberg SD, Adams AD, Harden RN, Bruehl S, Stanos SP, Houle T. Predicting total knee replacement pain: a prospective, observational study. Clin Orthop Relat Res. 2003;416: 27-36.

10. Brokelman RB, van Loon CJ, Rijnberg WJ. Patient versus surgeon satisfaction after total hip arthroplasty. J Bone Joint Surg Br. 2003;85:495-498.

11. Bunker JP Frazier HS, Mosteller F. 1 Improving health: measuring effects of medical care. Milbank Q. 1994;72:225-258.

12. Canadian Institute for Health Information. Hip and Knee Replacements in Canada; Canadian Joint Replacement Registry (CJRR) 2013 Annual Report. May 2013:94. Available at: http:// www.cihi.ca/CIHI-ext-portal/internet/EN/TabbedContent/types+ of +care/specialized+services/joint+replacements/cihi021359\#_ Reports_and_Analyses. Accessed February 16, 2014.

13. Ellis HB, Howard KJ, Khaleel MA, Bucholz R. Effect of psychopathology on patient-perceived outcomes of total knee arthroplasty within an indigent population. J Bone Joint Surg Am. 2012;94:e84.

14. Engel C, Hamilton NA, Potter PT, Zautra AJ. Impact of two types of expectancy on recovery from total knee replacement surgery (TKR) in adults with osteoarthritis. Behav Med. 2004;30: 113-123.

15. Escobar A, Quintana JM, Bilbao A, Azkarate J, Guenaga JI, Arenaza JC, Gutierrez LF. Effect of patient characteristics on reported outcomes after total knee replacement. Rheumatology (Oxford). 2007;46:112-119.

16. Ethgen O, Bruyere O, Richy F, Dardennes C, Reginster JY. Health-related quality of life in total hip and total knee arthroplasty: a qualitative and systematic review of the literature. $J$ Bone Joint Surg Am. 2004;86:963-974.

17. Fitzgerald JD, Orav EJ, Lee TH, Marcantonio ER, Poss R, Goldman L, Mangione CM. Patient quality of life during the 12 months following joint replacement surgery. Arthritis Rheum. 2004;51:100-109.

18. Gandhi R, Davey JR, Mahomed NN. Predicting patient dissatisfaction following joint replacement surgery. $J$ Rheumatol. 2008;35:2415-2418.

19. Gandhi R, Dhotar H, Razak F, Tso P, Davey JR, Mahomed NN. Predicting the longer term outcomes of total knee arthroplasty. Knee. 2010;17:15-18.

20. Gandhi R, Tsvetkov D, Dhottar H, Davey JR, Mahomed NN. Quantifying the pain experience in hip and knee osteoarthritis. Pain Res Manag. 2010;15:224-228.

21. Hall-Lord ML, Steen B, Larsson G. Postoperative experiences of pain and distress in elderly patients: an explorative study. Aging. 1999;11:73-82.

22. Harris IA, Harris AM, Naylor JM, Adie S, Mittal R, Dao AT. Discordance between patient and surgeon satisfaction after total joint arthroplasty. J Arthroplasty. 2013;28:722-727.

23. Hawker G, Wright J, Coyte P, Paul J, Dittus R, Croxford R, Katz B, Bombardier C, Heck D, Freund D. Health-related quality of life after knee replacement. J Bone Joint Surg Am. 1998;80:163173.

24. Heck DA, Robinson RL, Partridge CM, Lubitz RM, Freund DA. Patient outcomes after knee replacement. Clin Orthop Relat Res. 1998;356:93-110.

25. Higgins JP, Green S, eds. Cochrane Handbook for Systematic Reviews of Interventions Version 5.1.0 [updated March 2011]. The Cochrane Collaboration 2011. Available from http:// community.cochrane.org/handbook. Accessed February 1, 2014.

26. Jones CA, Voaklander DC, Suarez-Almazor ME. Determinants of function after total knee arthroplasty. Phys Ther. 2003;83:696-706.

27. Judge A, Arden NK, Cooper C, Kassim Javaid M, Carr AJ, Field RE, Dieppe PA. Predictors of outcomes of total knee replacement surgery. Rheumatology (Oxford). 2012;51:1804-1813.

28. Kim TK, Chang CB, Kang YG, Kim SJ, Seong SC. Causes and predictors of patient's dissatisfaction after uncomplicated total knee arthroplasty. J Arthroplasty. 2009;24:263-271.

29. Ko Y, Narayanasamy S, Wee HL, Lo NN, Yeo SJ, Yang KY, Yeo W, Chong HC, Thumboo J. Health-related quality of life after total knee replacement or unicompartmental knee arthroplasty in an urban Asian population. Value Health. 2011;14:322-328.

30. Kurtz S, Ong K, Lau E, Mowat F, Halpern M. Projections of primary and revision hip and knee arthroplasty in the United States from 2005 to 2030. J Bone Joint Surg Am. 2007;89:780785 .

31. Leskinen J, Eskelinen A, Huhtala H, Paavolainen P, Remes V. The incidence of knee arthroplasty for primary osteoarthritis grows rapidly among baby boomers: a population-based study in Finland. Arthritis Rheum. 2012;64:423-428.

32. Lieberman JR, Dorey F, Shekelle P, Schumacher L, Thomas BJ, Kilgus DJ, Finerman GA. Differences between patients' and physicians' evaluations of outcome after total hip arthroplasty. $J$ Bone Joint Surg Am. 1996;78:835-838.

33. Lingard EA, Katz JN, Wright EA, Sledge CB; Kinemax Outcomes Group. Predicting the outcome of total knee arthroplasty. $J$ Bone Joint Surg Am. 2004;86:2179-2186.

34. Lingard EA, Riddle DL. Impact of psychological distress on pain and function following knee arthroplasty. J Bone Joint Surg Am. 2007;89:1161-1169. 
35. Masselin-Dubois A, Attal N, Fletcher D, Jayr C, Albi A, Fermanian J, Bouhassira D, Baudic S. Are psychological predictors of chronic postsurgical pain dependent on the surgical model? A comparison of total knee arthroplasty and breast surgery for cancer. J Pain. 2013;14:854-864.

36. Noble PC, Gordon MJ, Weiss JM, Reddix RN, Conditt MA, Mathis KB. Does total knee replacement restore normal knee function? Clin Orthop Relat Res. 2005;431:157-165.

37. Papakostidou I, Dailiana ZH, Papapolychroniou T, Liaropoulos L, Zintzaras E, Karachalios TS, Malizos KN. Factors affecting the quality of life after total knee arthroplasties: a prospective study. BMC Musculoskelet Disord. 2012;13:116.

38. Pynsent PB, Adams DJ, Disney SP. The Oxford hip and knee outcome questionnaires for arthroplasty.[Erratum appears in $J$ Bone Joint Surg Br. 2005;87:1166]. J Bone Joint Surg Br. 2005;87:241-248.

39. Riddle DL, Wade JB, Jiranek WA, Kong X. Preoperative pain catastrophizing predicts pain outcome after knee arthroplasty. Clin Orthop Relat Res. 2010;468:798-806.

40. Rissanen P, Aro S, Sintonen H, Slatis P, Paavolainen P. Quality of life and functional ability in hip and knee replacements: a prospective study. Qual Life Res. 1996;5:56-64.

41. Robertsson O, Dunbar M, Pehrsson T, Knutson K, Lidgren L. Patient satisfaction after knee arthroplasty: a report on 27,372 knees operated on between 1981 and 1995 in Sweden. Acta Orthop Scand. 2000;71:262-267.

42. Roth ML, Tripp DA, Harrison MH, Sullivan M, Carson P. Demographic and psychosocial predictors of acute perioperative pain for total knee arthroplasty. Pain Res Manag. 2007;12:185194.

43. Rothwell AG, Hooper GJ, Hobbs A, Frampton CM. An analysis of the Oxford hip and knee scores and their relationship to early joint revision in the New Zealand Joint Registry. $J$ Bone Joint Surg Br. 2010;92:413-418.

44. Scott CE, Howie CR, MacDonald D, Biant LC. Predicting dissatisfaction following total knee replacement: a prospective study of 1217 patients. J Bone Joint Surg Br. 2010;92:1253-1258.

45. Singh JA, O’Byrne MM, Colligan RC, Lewallen DG. Pessimistic explanatory style: a psychological risk factor for poor pain and functional outcomes two years after knee replacement. $J$ Bone Joint Surg Br. 2010;92:799-806.

46. Smith BW, Zautra AJ. The role of purpose in life in recovery from knee surgery. Int J Behav Med. 2004;11:197-202.

47. Sullivan M, Tanzer M, Reardon G, Amirault D, Dunbar M, Stanish W. The role of presurgical expectancies in predicting pain and function one year following total knee arthroplasty. Pain. 2011;152:2287-2293.

48. Wells GA, Shea B, O'Connell D, Peterson J, Welch V, Losos M, Tugwell P. The Newcastle-Ottawa Scale (NOS) for assessing the quality of nonrandomised studies in meta-analyses. Ottawa Hospital Research Institute. Available at: http://www.ohri.ca/programs/ clinical_epidemiology/oxford.asp. Accessed January 4, 2014.

49. Williams DP, Blakey CM, Hadfield SG, Murray DW, Price AJ, Field RE. Long-term trends in the Oxford knee score following total knee replacement. Bone Joint J. 2013;95:45-51.

50. Wylde V, Dixon S, Blom AW. The role of preoperative selfefficacy in predicting outcome after total knee replacement. Musculoskelet Care. 2012;10:110-118.

51. Wylde V, Learmonth I, Potter A, Bettinson K, Lingard E. Patientreported outcomes after fixed- versus mobile-bearing total knee replacement: a multi-centre randomised controlled trial using the Kinemax total knee replacement. [Erratum appears in $J$ Bone Joint Surg Br. 2008;90:1534]. J Bone Joint Surg Br. 2008;90: 1172-1179. 